Fernandes, L.L.A, Rocha, M. J, Costa, Dayana B. (2019). "Prediction of Environmental Performance Indicators For Construction Sites Based on Artificial Neural Networks" In: Proc. $27^{\text {th }}$ Annual Conference of the International. Group for Lean Construction (IGLC), Pasquire C. and Hamzeh F.R. (ed.), Dublin, Ireland, pp. 1413-1424. DOI: https://doi.org/10.24928/2019/0248 Available at: <www.iglc.net>.

\title{
PREDICTION OF ENVIRONMENTAL PERFORMANCE INDICATORS FOR CONSTRUCTION SITES BASED ON ARTIFICIAL NEURAL NETWORKS
}

\author{
Luara L. A. Fernandes', Mércurie J. Rocha ${ }^{2}$, and Dayana B. Costa ${ }^{3}$
}

\begin{abstract}
The construction sector still contributes on a major scale to negative impacts on the environment, but it is aware of its responsibility for sustainability in the life cycle of a building. The sector has been using performance measurement, specifically environmental indicators, to monitor and manage its impacts. However, managers have not been using the monitored indicators for any managerial decision because they do not have benchmarks to establish performance targets and evaluate their results. This research is an experimental study that aims to develop an equation for the prediction of environmental performance indicators based on the construction progress. For the development of the study, a database of 15 construction sites in Brazil concerning three environmental indicators (water consumption, energy consumption and construction waste generation) established by the PBQP-H (The Brazilian Program for Quality and Productivity in Habitat) was used. The developed software was written in Python language and the model was built with the use of Artificial Neural Networks. From the application of the resulting equations, managers can obtain a benchmark based on the construction progress in which the building is and promote improvements in their environmental performance as well as use such information in the planning stage.
\end{abstract}

\section{KEYWORDS}

Lean construction, sustainability, waste, construction management, performance measurement.

MSc Student, Civil Engineering Post Graduation Program, Federal University of Bahia, BA, 40210-630, BRA, luara.fernandes@gmail.com

2 PhD Student, Civil Engineering Post Graduation Program, Federal University of Bahia, BA, 40210-630, BRA, mercurie_janeai@hotmail.com

3 Associate Professor, School of Engineering, Department of Structural and Construction Engineering, Federal University of Bahia, BA, 40210-630, BRA, dayanabcosta@ufba.br 


\section{INTRODUCTION}

Lean construction can support sustainable construction by not focusing only on its accidental benefits for the environment, but also introducing the social and environmental issues as values to reach (Bae and Kim 2007). Lean construction can contribute to more sustainable buildings, since they add value to the customer, intervening at the stages of conception and design and at time of construction, (Carneiro et al. 2012). A more sustainable construction should seek increase value, pollute less, provide support for the sustainable use of resources, respond effectively to the parties involved and improve the quality of life in the present without compromising the future (Silva 2003).

Lean construction implementation on construction sites reduces waste and improves construction flows, providing economic advantages (Carneiro et al. 2012), but it is essential to ensure sustainability, also improve the social and environmental aspects during the lifecycle (Carneiro et al. 2012). Lean construction principles can contribute to the sustainability purposes by eliminating waste (of material) by minimizing resource depletion and pollution and adding value to the customer, with the reduction of these resources, and matching business and environmental excellence (Bae and Kim 2007).

For the management of the impacts, it is necessary to define technological resources and necessary managerial actions, selecting the resources required to be implemented and the deadlines and costs involved (Cardoso and Araujo 2007). In this way, the environmental management of construction sites uses sustainability indicators to monitor the conditions and environmental performance of construction sites (Tam et al. 2006).

In Brazil, there are efforts to define sustainability indicators in different scales of the built environment, which vary widely and are defined based on criteria and methodologies not necessarily replicable (Silva 2007). The PBQP-H (Brazilian Program for Quality and Productivity in Habitat) requires that the certified companies in this Program collect six sustainability indicators, which are: (1) energy consumption throughout the construction ( $\mathrm{kWh} /$ number of workers); (2) energy consumption at the end of the construction (kWh / $\mathrm{m}^{2}$ ); (3) waste generation throughout the construction ( $\mathrm{m}^{3} /$ number of workers); (4) waste generation at the end of the construction $\left(\mathrm{m}^{3} / \mathrm{m}^{2}\right)$; (5) water consumption throughout the construction ( $\mathrm{m}^{3} /$ number of workers); (6) water consumption at the end of the construction $\left(\mathrm{m}^{3} / \mathrm{m}^{2}\right)$.

However, just the collection of indicators is not enough to improve environmental performance. Sustainability indicators are generally new, and the main problem is to establish maximum and minimum values (Lopez and Sanchez 2011). Therefore, the purpose of this study is to make a statistical analysis of a database of the three environmental PBQP-H indicators throughout the construction and to develop an equation relating them to the construction progress. The developed equation aims to provide a forecast of these environmental indicators during the construction, supporting the construction industry and firms in the improvement of their environmental performance. 


\section{SUSTAINABILITY MANAGEMENT IN CONSTRUCTION}

According to Yilmaz and Bakis (2015), sustainability is the use of natural resources in an equilibrium condition that it does not reach decay, depletion and non-renewal, without compromising the development of future generations. The concept fundamentally seeks to promote balance with respect to the human, time and place; in other words, equitable allocation of the world's resources among all nations, living beings, and future generations (Yilmaz and Bakis 2015). Sustainability has become a strategy that led governments to develop policies and corporations to develop strategies (Ratiu and Anderson 2015). The construction industry is becoming aware of the importance of adopting the principles of sustainability in the sector and has been using statistical and computational methods to perform analysis to improve environmental performance.

Sustainable construction is related to the integration of environmental, social and economic considerations into building business strategies and practices (Ogunbihy et al. 2014). It is a holistic process that seeks to maintain the harmony between the natural and constructed environment (Yilmaz and Bakis 2015). Sustainable construction is directly linked to sustainable project management.

According to ISO 14001/2015, it is the role of an Environmental Management System (EMS) to help organizations prevent and control significant impacts to the environment, manage risks and continuously improve environmental performance and productivity. Performance measurement is a strategy that can be used to monitor environmental impacts.

Performance measurement is very important for production management because it provides necessary information to control the process, and makes possible the establishment of challenging and viable goals (Lantelme and Formoso 2000). Indicators can be an efficient tool to measure environmental performance. Sustainability indicators can be defined as instruments that allow the description of environmental, economic and social impacts caused by enterprises (Silva 2007). By monitoring these indicators, regular evaluations and goal control can be performed, since they can highlight any adverse trends in the environmental control process (Tam et al. 2006).

However, for an effective use of monitored indicators, it is necessary reference values. According to La Barre and El-Adayay (2014), one of the most important aspect of performance measurement is the ability to do benchmark. It is the next step for improving efficiency of products and processes (Luu et al 2008).

\section{ARTIFICIAL NEURAL NETWORKS}

A machine learning system is a computational program that takes decisions based on accumulated experiences through the effective resolution of previous problems (Monard and Baranauskas 2003). Artificial Neural Networks is an example of an Artificial Neural Network technique. A neural network "is a massively distributed processor composed of simple processing unit, which has the natural propensity to store experimental knowledge and make it available for use" (Haykin 2007). It resembles the human brain in two respects: in the form of acquiring knowledge (from its environment and in a learning process) and 
in the storage of knowledge (through synaptic weights, which are the connecting forces between neurons) (Haykin 2007).

Neto, Nagahama and Gadéa (2017) point out that neural networks have been widely used in engineering as a solution to complex and non-linear problems. One of the applications is the use of neural networks to extract rules and make a sensitivity analysis, a possibility pointed out with one of the potentialities of the method of Han and Kamber (2001). The search for rules that explain the behavior of observed variables can be seen, for example, in Bortolazza and Formoso (2006), that studied the correlation between root cause frequency and PPC measured weekly in sites that implemented Last Planner. Due to the number of indicators and, therefore, variables produced in the sustainable management of buildings, there is a great potential to develop more studies of this nature.

\section{RESEARCH METHOD}

This research is characterized as experimental study, which is, according to Fontelles et al (2009), any research that involves experiments. In this kind of study, the researcher selects the variables that are going to be studied, defines the manner of control and makes the observation of the effects of the research (Fontelles 2009).

This study was developed based on a data collection carried out by the Research Group in Construction Management and Technology ${ }^{4}$. For this paper, data from three environmental indicators (water consumption throughout the construction, energy consumption throughout the construction and waste generation throughout the construction) and the physical progress of construction projects were used. All the indicators used were collected from a monthly basis by the construction projects investigated. The pilot sample used for this paper is composed by 15 construction sites, with different constructive systems, which are concrete walls (5), reinforced concrete (5) and structural masonry (5), from different target public, which are high income (5) and low income (10), and with different building purposes, which are commercial (4) and residential (11). The Figure 1 presents the characterization of the sample.
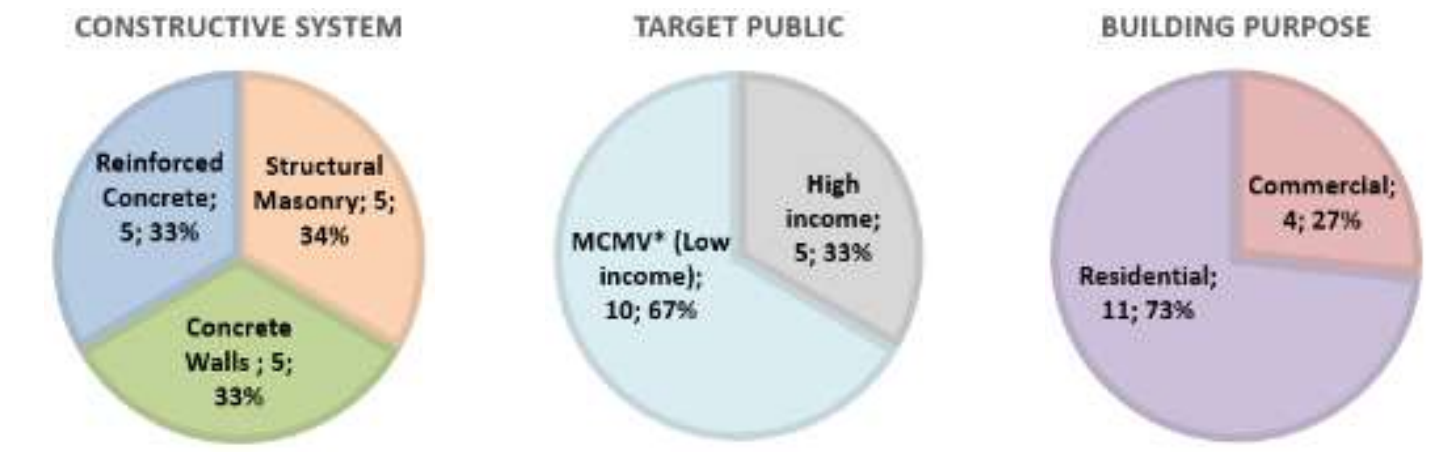

*MCMV is the Brazilian government housing program

Figure 1 - Sample characterization

\footnotetext{
${ }^{4}$ Research Group in Construction Management and Technology (GETEC), Department of Structural and Construction Engineering, Federal University of Bahia, BA, Brazil (www.getec.eng.ufba.br)
} 
The study was developed from four major steps: (1) Sample analysis, (2) Equation development, (3) Evaluation of the model (4) Final model, as illustrated in Figure 2.

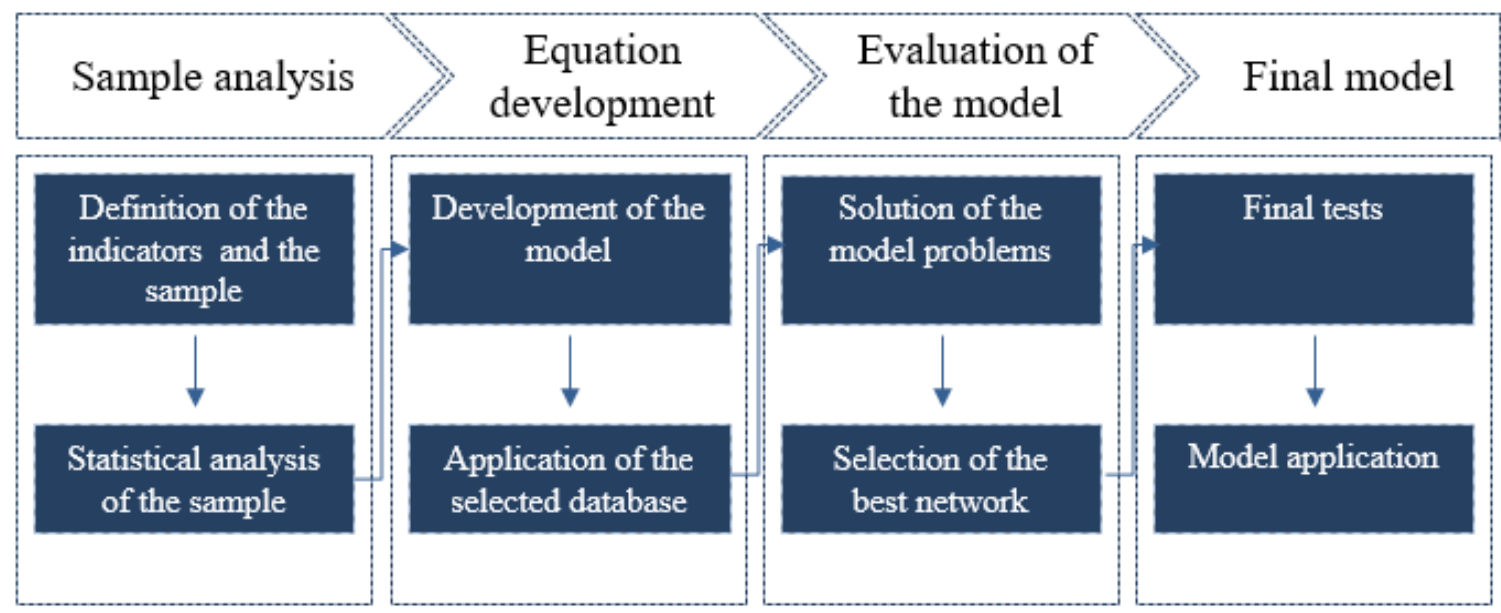

Figure 2 - Steps of the study

The first stage of the study was consisted in defining the indicators and the sample to develop a statistical analysis. Then, a software was written in Python with the use of the scikit-learn library (Pedregosa et al, 2011) and in its implementation was used Multi-layer Perceptron. Only one intermediate layer was applied in the model, considering the good results (Neto et al. 2017). Several network topologies (from one to seven neurons in this layer) were tested respecting the Komogorov-Nielsen theorem (Kóvacs 1996). The transfer functions tested were the logarithmic and hyperbolic tangent.

After these steps, some Artificial Neural Networks were trained in order to predict the sustainability indicators based on the physical progress of the constructions. Table 1 presents the variables in the model and their range of variation.

Table 1 - Variables, representation and range of variation

\begin{tabular}{ccc}
\hline Variable & Representation & Range of variation \\
\hline Physical progress & $\mathrm{x} 0$ & {$[0 ; 1]$} \\
Water consumption & $\mathrm{y} 0$ & {$[0 ; \infty)$} \\
Energy consumption & $\mathrm{y} 1$ & {$[0 ; \infty)$} \\
Waste generation & $\mathrm{y} 2$ & {$[0 ; \infty)$} \\
\hline
\end{tabular}

For this data analysis, cumulative medians of indicators of 15 construction sites were used for each $10 \%$ of physical progress (except for the first data range, which was used $5 \%$ to analyze the impacts of the activities of the beginning of the construction, and the last data range, which was used $15 \%$ due to the proximity to the end of the construction). The data waTable 2 presents the data set used in the model. 
Table 2 - Data set used in the study

\begin{tabular}{cccc}
\hline $\begin{array}{c}\text { Construction } \\
\text { progress (\%) }\end{array}$ & $\begin{array}{c}\text { Water consumption } \\
{\text { ( } \mathbf{m}^{\mathbf{3}} \text { / number of }}_{\text {workers) }}\end{array}$ & $\begin{array}{c}\text { Energy } \\
\text { consuption } \\
\text { (KWh / number of } \\
\text { workers) }\end{array}$ & $\begin{array}{c}\text { Waste } \\
\text { generation } \text { ( }^{\mathbf{3}} / \\
\text { number of } \\
\text { workers) }\end{array}$ \\
\hline $0-5$ & 0.97 & 67.21 & 0.31 \\
$5-15$ & 2.71 & 84.96 & 0.77 \\
$15-25$ & 4.49 & 101.13 & 1.29 \\
$25-35$ & 5.61 & 119.24 & 2.15 \\
$35-45$ & 7.09 & 140.81 & 2.75 \\
$45-55$ & 8.88 & 158.85 & 3.37 \\
$55-65$ & 10.58 & 177.66 & 4.07 \\
$65-75$ & 12.13 & 193.68 & 4.94 \\
$75-85$ & 13.94 & 212.81 & 5.77 \\
$85-100$ & 16.32 & 230.62 & 6.83 \\
\hline
\end{tabular}

\section{RESULTS AND DISCUSSION}

This section presents the results obtained from the statistical analysis of the sample and the generation of the model.

\section{STATISTICAL ANALYSIS OF THE ENVIRONMENTAL PERFORMANCE INDICATORS}

A statistical analysis of the sample was performed in order to identify the range of construction progress with major impacts and establish some reference values. Regarding to the water consumption indicator, the median values varied between $0.97 \mathrm{~m}^{3} /$ worker and $2.38 \mathrm{~m}^{3} /$ worker. The maximum value for this indicator is associated with the range of construction progress of $85-100 \%$, which may be related to the reduction of the number of workers in the end of the construction, what impacts in the indicator because it consider this variable in its denominator. The minimum value is associated with the $0-5 \%$ range of construction progress, what is expected due to the small amount of activities at the beginning of the construction.

For the energy consumption indicator, the median values varied between 16.02 $\mathrm{kWh} /$ worker and $67 \mathrm{kWh} /$ worker. It should be noted that for this indicator the maximum value is associated with $0-5 \%$ range of construction progress. Analyzing the data, it was noticed that this value is specifically high due the small amount of data for this range (not all the sites have the energy consumption measures in the beginning of the construction) and also due to one construction site that present an extreme indicator in the deployment phase. However, the medium values for all the other construction progress are in the range of $16.02 \mathrm{kWh} /$ worker and $21.57 \mathrm{kWh}$ /worker, presenting a certain regularity of the data.

The waste generation indicator presented median values between $0.31 \mathrm{~m}^{3} /$ worker (range of $0-5 \%$ of construction progress) and $1.06 \mathrm{~m}^{3} /$ worker (range of $85-100 \%$ of construction progress). This situation is expected because the indicator does not consider soil for waste, which in general is the biggest part of the waste in the beginning of the construction. The 
fact that the biggest value for the indicator is in the end of the construction is also expected due to the demobilization phase. The complete statistical analysis of the data is presented in Table 3.

Table 3 - Statistical analysis of the sample

\begin{tabular}{|c|c|c|c|c|c|c|}
\hline & $\begin{array}{c}\text { Construction } \\
\text { progress }\end{array}$ & Minimum & Average & Median & Maximum & $\begin{array}{l}\text { Standard } \\
\text { deviation }\end{array}$ \\
\hline \multirow{10}{*}{ 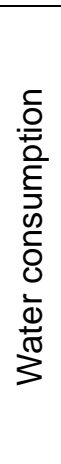 } & $0-5 \%$ & 0.60 & 1.50 & 0.97 & 3.44 & 1.34 \\
\hline & $5-15 \%$ & 0.29 & 1.80 & 1.74 & 4.50 & 1.31 \\
\hline & $15-25 \%$ & 0.02 & 2.43 & 1.78 & 10.84 & 2.67 \\
\hline & $25-35 \%$ & 0.08 & 2.23 & 1.12 & 8.98 & 2.60 \\
\hline & $35-45 \%$ & 0.50 & 2.13 & 1.48 & 6.31 & 1.80 \\
\hline & $45-55 \%$ & 0.47 & 2.23 & 1.79 & 7.32 & 1.91 \\
\hline & $55-65 \%$ & 0.28 & 2.36 & 1.70 & 6.48 & 1.84 \\
\hline & $65-75 \%$ & 0.14 & 2.60 & 1.55 & 11.66 & 2.97 \\
\hline & $75-85 \%$ & 0.13 & 1.95 & 1.81 & 3.65 & 0.90 \\
\hline & $85-100 \%$ & 0.14 & 2.33 & 2.38 & 4.88 & 1.37 \\
\hline \multirow{9}{*}{ 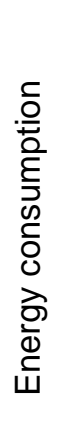 } & $0-5 \%$ & 16.13 & 67.21 & 67.21 & 118.28 & 72.23 \\
\hline & $5-15 \%$ & 0.83 & 18.06 & 17.75 & 37.20 & 12.64 \\
\hline & $15-25 \%$ & 3.94 & 29.60 & 16.17 & 185.78 & 38.36 \\
\hline & $25-35 \%$ & 0.73 & 19.51 & 18.11 & 49.65 & 12.89 \\
\hline & $35-45 \%$ & 7.98 & 20.86 & 21.57 & 44.19 & 10.16 \\
\hline & $45-55 \%$ & 6.27 & 19.10 & 18.04 & 35.53 & 9.81 \\
\hline & $55-65 \%$ & 5.50 & 20.35 & 18.81 & 37.28 & 10.62 \\
\hline & $65-75 \%$ & 5.27 & 20.68 & 16.02 & 42.31 & 10.62 \\
\hline & $75-85 \%$ & 2.94 & 19.54 & 19.13 & 44.37 & 10.93 \\
\hline \multirow{11}{*}{ 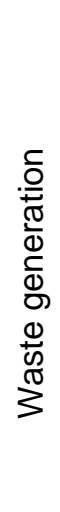 } & $85-100 \%$ & 1.88 & 20.59 & 17.81 & 47.50 & 13.45 \\
\hline & $0-5 \%$ & 0.13 & 0.31 & 0.31 & 0.49 & 0.25 \\
\hline & $5-15 \%$ & 0.08 & 2.78 & 0.46 & 34.31 & 8.74 \\
\hline & $15-25 \%$ & 0.02 & 4.00 & 0.52 & 33.98 & 9.98 \\
\hline & $25-35 \%$ & 0.09 & 1.34 & 0.86 & 8.99 & 2.11 \\
\hline & $35-45 \%$ & 0.17 & 0.80 & 0.60 & 2.99 & 0.75 \\
\hline & $45-55 \%$ & 0.15 & 1.27 & 0.63 & 3.75 & 1.23 \\
\hline & $55-65 \%$ & 0.18 & 0.88 & 0.70 & 2.36 & 0.55 \\
\hline & $65-75 \%$ & 0.19 & 1.09 & 0.87 & 3.04 & 0.77 \\
\hline & $75-85 \%$ & 0.43 & 1.07 & 0.83 & 2.50 & 0.62 \\
\hline & $85-100 \%$ & 0.25 & 1.15 & 1.06 & 2.34 & 0.69 \\
\hline
\end{tabular}

\section{EQUATIONS FOR THE PREDICTION OF ENVIRONMENTAL PERFORMANCE INDICATORS BASED ON THE CONSTRCTION PROGRESS}

The quality of the trained networks prediction can be measured by the $\mathrm{R}^{2}$ resulting from the linear adjustment between the values predicted by the network and those values effectively measured; the closer the prediction is to 1 the better. In addition, it is possible 
to evaluate individually the error of the network in making the forecast for each of the output variables of the database presented during the training, in order to know the errors for the dataset. The closer to $0 \%$ errors are, the better the network. The $\mathrm{R}^{2}$ was evaluated for the 3 output variables together and the error was evaluated for each individually, seeking to identify which could cause errors or deviations in the forecast. The results obtained are presented in Table 4.

Table 4 - Results obtained from the trained networks

\begin{tabular}{|c|c|c|c|c|}
\hline Function & $\mathbf{R}^{2}$ & Variable & $\begin{array}{c}\text { Maximum } \\
\text { negative error }\end{array}$ & $\begin{array}{c}\text { Minimum negative } \\
\text { error }\end{array}$ \\
\hline & & y0 & -10.26 & 5.17 \\
\hline \multirow[t]{3}{*}{1} & 0.9996 & $\mathrm{y} 1$ & -1.33 & 0.86 \\
\hline & & $y 2$ & -79.97 & 7.64 \\
\hline & & y0 & -9.55 & 21.19 \\
\hline \multirow[t]{3}{*}{2} & 0.9998 & $\mathrm{y} 1$ & -1.50 & 0.96 \\
\hline & & y2 & -36.31 & 9.81 \\
\hline & & y0 & -6.96 & 4.20 \\
\hline \multirow[t]{3}{*}{3} & 0.9999 & $\mathrm{y} 1$ & -0.65 & 0.50 \\
\hline & & y2 & -5.92 & 4.82 \\
\hline & & y0 & -3.18 & 2.85 \\
\hline \multirow[t]{3}{*}{4} & 1.0000 & $\mathrm{y} 1$ & -0.01 & 0.01 \\
\hline & & y2 & -8.46 & 7.06 \\
\hline & & y0 & -2.71 & 1.68 \\
\hline \multirow[t]{3}{*}{5} & 1.0000 & $\mathrm{y} 1$ & -0.01 & 0.02 \\
\hline & & y2 & -10.33 & 7.63 \\
\hline & & y0 & -3.01 & 3.39 \\
\hline \multirow[t]{3}{*}{6} & 1.0000 & $\mathrm{y} 1$ & -0.02 & 0.02 \\
\hline & & y2 & -5.41 & 7.79 \\
\hline & & y0 & -0.30 & 1.19 \\
\hline \multirow[t]{2}{*}{7} & 1.0000 & $\mathrm{y} 1$ & -0.03 & 0.02 \\
\hline & & y2 & -2.26 & 2.35 \\
\hline
\end{tabular}

It could be verified initially by the $\mathrm{R}^{2}$ analysis the excellent results presented by the networks, obtaining a numerical value equal to 1.0000 for all the networks with more than 3 neurons in the intermediate layer. On the other hand, the best network, according to Neto et al. (2017), is the network that produces errors of less than $10 \%$, in absolute values, for all output variables. The networks that met these criteria were the ones with 3, 4, 6 and 7 neurons in the intermediate layer. In addition, the best network is the one with the lowest number of neurons possible (Neto et al. 2017), which is the one with 3 neurons. Furthermore, the adjusted equation becomes more complex as the number of neurons increases, so, in this situation, the network with only 3 neurons must be chosen. It should be noted that the prediction of variable y2, waste generation, was especially problematic, indicating a difficulty of the Artificial Neural Networks to recognize a pattern for this variable. This problem can be justified by the fact that managers often do not know 
effectively the amount of waste, due to inappropriate discards and lack of waste control. The Figure 3, Figure 4 and Figure 5 show the linear adjustment and the error distribution histogram for water consumption, energy consumption and waste generation, respectively.
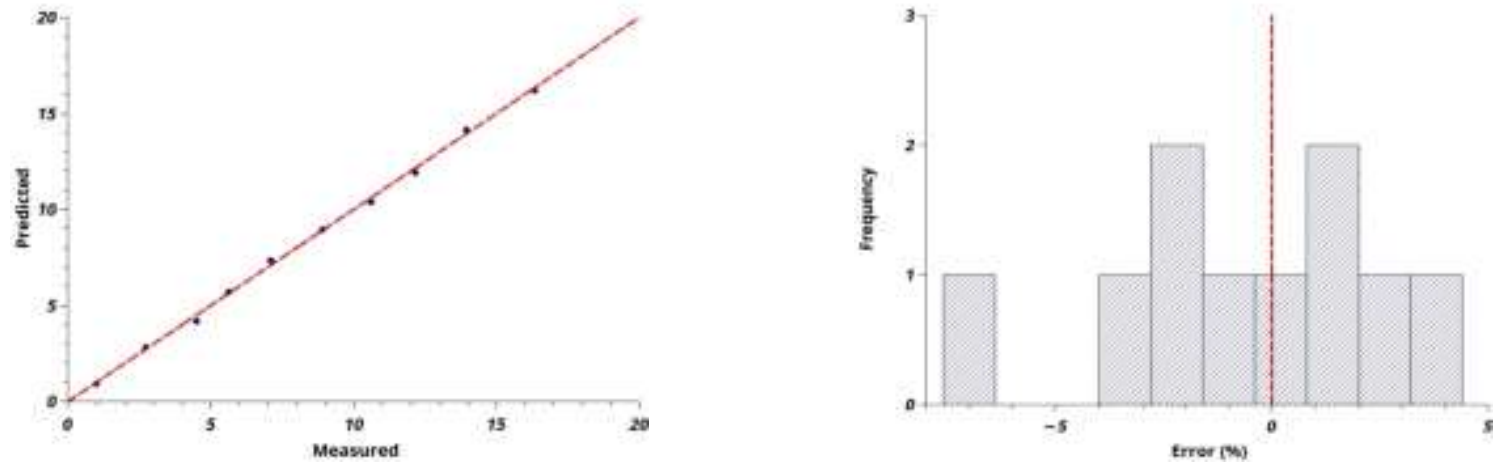

Figure 3 - Linear adjustment and error distribution histogram for the water consumption indicator
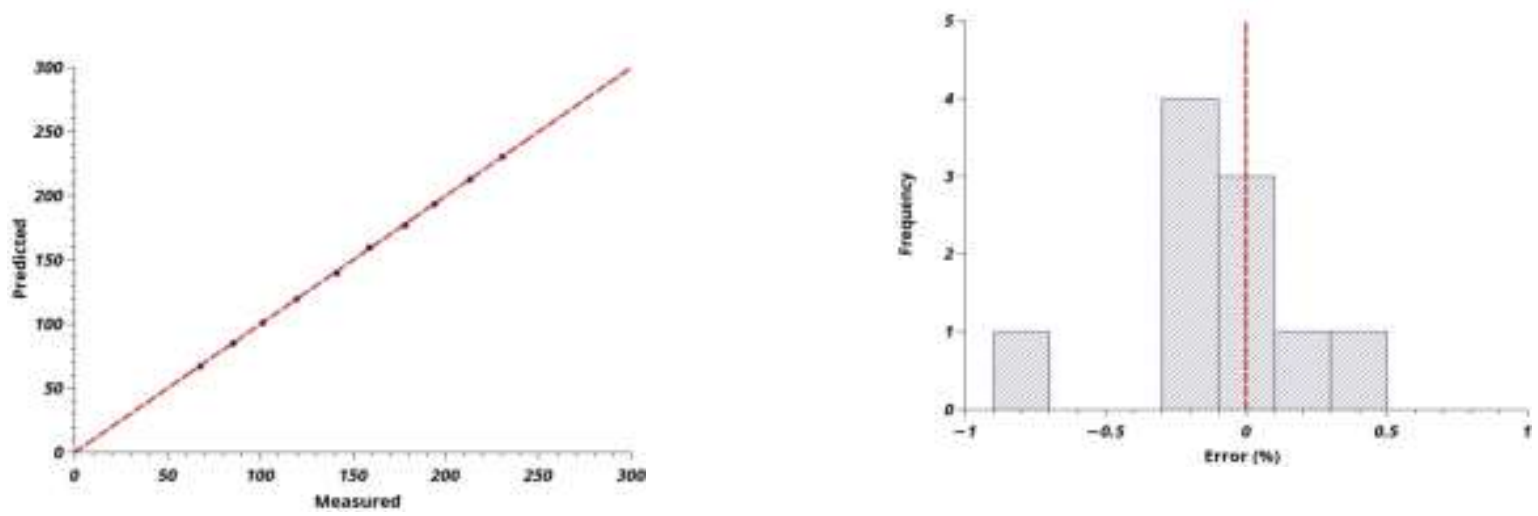

Figure 4 - Linear adjustment and the error distribution histogram for the energy consumption indicator
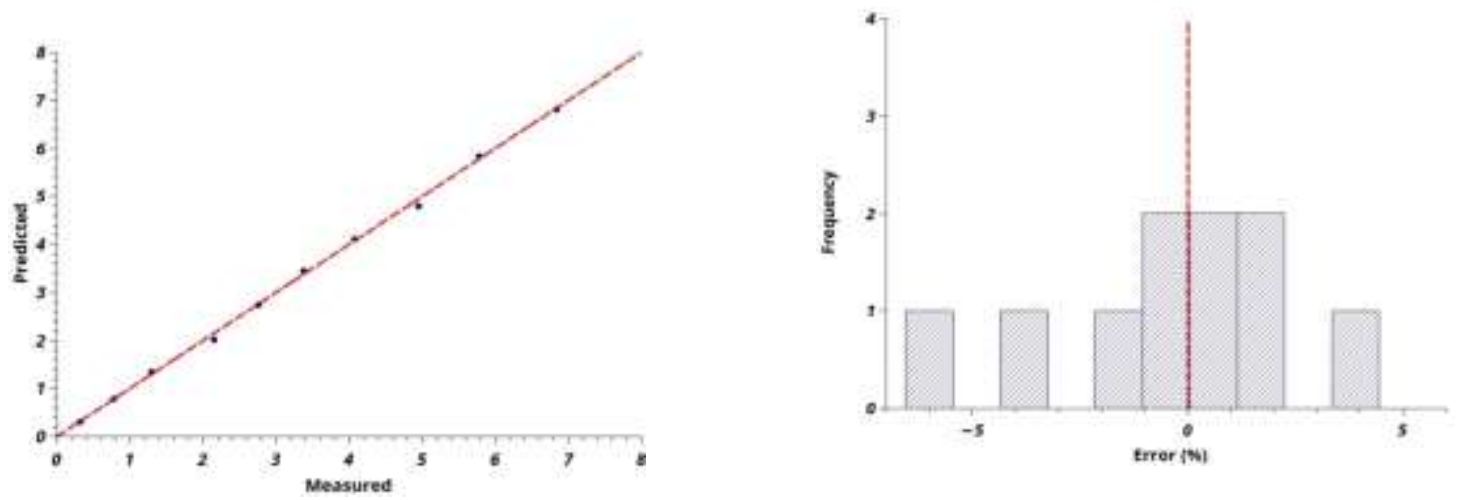

Figure 5 - Linear adjustment and the error distribution histogram for the waste generation indicator

Finally, the equations adjusted for the network are presented in Table 5. 
Table 5 - Equations adjusted for each environmental indicator

\begin{tabular}{c}
\hline Water consumption throughout the construction \\
\hline $\mathrm{y} 0=-3.5414+14.3485 /(1+7.2142 * \exp (-4.6260 * \mathrm{x} 0))+3.1105 /(1+46139674.6098$ \\
$* \exp (-21.1366 * \mathrm{x} 0))+3.3357 /(1+1.6709 * \exp (-27.5809 * \mathrm{x} 0))$ \\
Energy consumption throughout the construction \\
$\mathrm{y} 1=26.2729+175.9568 /(1+7.214 * \exp (-4.6260 * \mathrm{x} 0))+19.5838 /(1+$ \\
$46139674.6098 * \exp (-21.1366 * \mathrm{x} 0))+21.0000 /(1+1.6709 * \exp (-27.5809 * \mathrm{x} 0))$ \\
Waste generation throughout the construction \\
\hline $\mathrm{y} 2=-0.7561+6.3319 /(1+7.2142 * \exp (-4.6260 * \mathrm{x} 0))+1.5226 /(1+$ \\
$46139674.6098 * \exp (-21.1366 * \mathrm{x} 0))+0.17198 /(1+1.6709 * \exp (-27.5809 * \mathrm{x} 0))$ \\
\hline
\end{tabular}

From these equations, it is possible for the project managers to forecast environmental indicators based on the construction progress. At first sight, its application may not be simple if it is thought to calculate by hand, but such equations in this format can easily be implemented in some spreadsheet, app or website that automatically calculates the measures taking with single input variable the physical progress of the construction site. The development of this model presents its relevance as it shows a reference so that managers can make managerial decisions and improve the environmental performance of the construction.

\section{CONCLUSIONS}

From the results obtained in this study it was evidenced that it is possible to apply Artificial Neural Networks to make correlations between environmental indicators and construction progress, obtaining a predictive model. The data set with the logarithmic transfer function used in the networks presented the best performance, being the network with 5 neurons in the intermediate layer the best for the development of the model. It should be noted that, among the 3 indicators, the waste generation was the one that presented more problem for the calibration of the model.

In addition, the use of median values to represent results of a set of construction sites was observed in this study as an alternative to avoid the inherent variability to the constructive process that appear naturally in the indicators. However, it can be considered a limitation of the study since it does not consider the specificities of each site.

In view of the good performance, it would be advisable to apply the technique to a larger set of data and verify the performance in this situation or even to seek new correlations in order to generate new forecasting models. To cope this limitation, a research project is under development in Brazil aiming to obtain data related to the environmental performance measures presented in this work from at least 100 construction sites national wide. Thus, future studies intent to develop an equation for different constructive methods in residential buildings, in order to achieve a more trustworthy benchmark. 


\section{REFERENCES}

Araujo, V. M. (2009) Práticas recomendadas para a gestão mais sustentável de canteiros de obras[Best practices for the most sustainable management of construction sites]. Master's Dissertation. Escola Politécnica da Universidade de Sao Paulo at Sao Paulo.

Bae, J. and Kim, Y.( 2007). "Sustainable Value on Construction Project and Application of Lean Construction Methods" Proc. of the 15th Ann. Conf. of the Int'l Group for Lean Construction. East Lansing, Michigan.

Bortolazza, R.C., Costa, D.B., Formoso, C.T. (2005). "A quantitative analysis of the implementation of the last planner system in Brazil" Proc. of the 13th Ann. Int'l Group for Lean Construction. Sydney, Australia.

Cardoso, F.F, Araujo, V.M. (2007). Levantamento do estado da arte: Canteiro de obras. Projeto Tecnologias para Construcao Habitacional mais Sustentavel. Sao Paulo: Finep 2386/04.

Carneiro, S.B.M. , Campos, I.B. , Oliveira, D.M.D., Neto, J.P.B. (2012), "Lean and Green: A Relationship Matrix" Proc of the 20th Ann. Conf. of the Int'l Group for Lean Construction. San Diego, USA.

Fontelles, M.J., Simões, M.G., Farias, S.H. and Fontelles, R.G.S. (2009) Scientific research methodology: Guidelines for elaboration of a research protocol. Revista Paraense de Medicina [Paraense Journal of Medicine], 23 (3).

Han, J., Kamber, M. (2001) Data Mining: concepts and techniques. Morgan Kaufmann Publishers.

Haykin, S. (2007). Neural Networks: Principles and Practices. 2 ed, 900p.

Ingrao, C., Messineo, A., Beltramo, R., Yigitcanlar, T., Ioppolo, G. (2018) . "How can life cycle thinking support sustainability of buildings? Investigating life cycle assessment applications for energy efficiency and environmental performance" Journal of Cleaner Production, 201, 556-569, 2018.

International Organization for Standardization (ISO). ISO/DIS 14001 Environmental management systems - Requirements with guidance for use.

Kovács, Z.L.L (1996). Redes neurais artificiais: fundamentos e aplicações [Artificial neural networks: fundamentals and applications]. São Paulo.

La Barre, P. S.; El-Adaway, I. H. "Project Benchmarking: Tool for Mitigating Conflicts, Claims, and Disputes through Improved Performance". Journal of Legal Affairs and Dispute Resolution in Engineering and Construction, [s. 1.], v. 6, n. 1, p. 04513003, 2014.

Lantelme, E., Formoso, C.T. (2000). "Improving Performance Through Measurement: The Application of Lean Production and Organisational Learning Principles" Proc of the 8th Ann. Conf. of the Int'l Group for Lean Construction.Brigthon, UK.

López, F.R., SÁNCHEZ, G.F. (2011). Challenges for Sustainability Assessment by Indicators. Leadership and Management in Engineering. 11, 321-325.

Luu, V.T., KIM, S., HUYNH, T. (2008) Improving project management performance of large contractors using benchmarking approach. Int. J. Project Manage. 26, 758-769.

Monard, M.C., Baranauskas, J. A. (2003) . Conceitos sobre aprendizado de máquina. Sistemas inteligentes-Fundamentos e aplicações [Concepts about machine learning. Intelligent systems-Fundamentals and applications], 1(1), 32. 
Neto, D.O.P, Nagahama, K.J., Gadéa, A. S. M. (2017) Determinação da tensão elástica de flambagem distorcional em perfis $\mathrm{z}$ enrigecidos [Determination of elastic tension of distorted flammability in z-shaped profiles]. South American Journal of Structural Engineering, 3.

Ogunbiyi, O., Oladapo, A.; Goulding, J. (2014). An empirical study of the impact of lean construction techniques on sustainable construction in the UK. Construction Innovation, $14(1), 88-107$.

Oliveira, J.A.C. (2011) Proposta de avaliação e classificação da sustentabilidade ambiental de canteiros de obras. Metodologia ECO OBRA aplicada no Distrito Federal - DF [Proposal for the evaluation and classification of the environmental sustainability of construction sites. Methodology ECO WORK applied in the Federal District - FD]. $\mathrm{PhD}$ thesis. Universidade de Brasília at Brasília.

Pedregosa, F., Varoquaux, G., Gramfort, A., Michel, V., Thirion, B., Grisel, O. and Blondel, M. and Prettenhofer, P., Weiss, R., Dubourg, V., Vanderplas, J., Passos, A., Cournapeau, D., Brucher, M., Perrot, M., Duchesnay, E. (2011) Scikit-learn: Machine Learning in Python, JMLR 12, 2825-2830.

Peng, C. (2016). Calculation of a building's life cycle carbon emissions based on Ecotect and building information modeling. Journal of Cleaner Production, 112.

Ratiu, C., Anderson, B.B. (2015) The multiple identities of sustainability. World Journal of Science, Technology and Sustainable Development, 12(3), 194-205.

Silva, V.G. (2003) Avaliação da sustentabilidade de edifícios de escritórios brasileiros: diretrizes e base metodológica [Sustainability evaluation of Brazilian office buildings: guidelines and methodological basis]. Thesis (Doctorate). Escola Politécnica da Universidade de São Paulo at São Paulo.

Silva, V.G. (2007) Indicadores de sustentabilidade de edifícios: estado da arte e desafios para desenvolvimento no Brasil [Sustainability indicators of buildings: state of the art and challenges for development in Brazil]. Ambiente Construído [Built Environment], 7(1), 47-66.

Tam, V.W.Y., Tam, C.M., Zeng, S.X., Chan, K.K. (2006) Environmental performance measurement indicators in construction. Building and Environmental, 41, 64-173.

Vasquez, E. et al. (2011) Sustainability in civil construction applied in the construction site phase. WIT Transactions on Ecology and the Environment, 144, 265-276.

Yilmaz, M., Bakis, A. (2015) Sustainability in Construction Sector. Procedia - Social And Behavioral Sciences, 195, 2253-2262. 